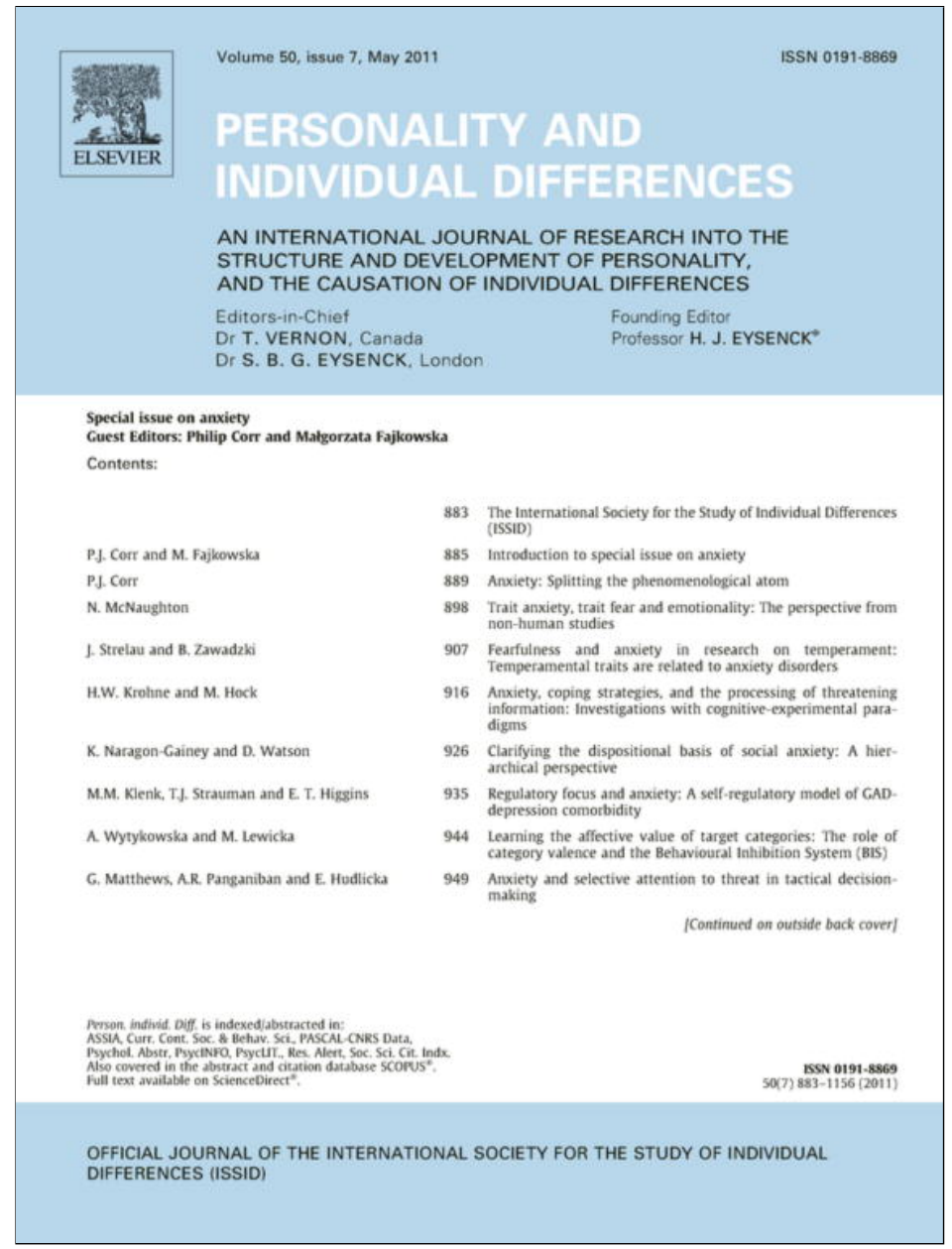

This article appeared in a journal published by Elsevier. The attached copy is furnished to the author for internal non-commercial research and education use, including for instruction at the authors institution and sharing with colleagues.

Other uses, including reproduction and distribution, or selling or licensing copies, or posting to personal, institutional or third party websites are prohibited.

In most cases authors are permitted to post their version of the article (e.g. in Word or Tex form) to their personal website or institutional repository. Authors requiring further information regarding Elsevier's archiving and manuscript policies are encouraged to visit:

http://www.elsevier.com/copyright 


\title{
Regulatory focus and anxiety: A self-regulatory model of GAD-depression comorbidity is
}

\author{
Megan M. Klenk ${ }^{a}$, Timothy J. Strauman ${ }^{a, *}$, E. Tory Higgins ${ }^{b}$ \\ a Duke University, Durham, NC, United States \\ ${ }^{\mathrm{b}}$ Columbia University, New York, NY, United States
}

\section{A R T I C L E I N F O}

\section{Article history:}

Received 11 May 2010

Received in revised form 29 November 2010

Accepted 1 December 2010

Available online 7 January 2011

\section{Keywords:}

Anxiety

Depression

Self-regulation

Regulatory focus theory

Self-discrepancy theory

Comorbidity

\begin{abstract}
A B S T R A C T
The etiology of generalized anxiety disorder (GAD), including its high degree of comorbidity with major depressive disorder (MDD), remains a conceptual and clinical challenge. In this article, we discuss the relevance of regulatory focus theory, an influential theory of self-regulation, for understanding vulnerability to GAD as well as GAD/MDD comorbidity. The theory postulates two systems for pursuing desired end states: the promotion and prevention systems. Drawing upon studies documenting the affective and motivational consequences of failing to attain promotion vs. prevention goals, as well as the literature linking promotion failure with depression, we propose how dysfunction within the prevention system could lead to GAD - with, as well as without, MDD.
\end{abstract}

(c) 2010 Elsevier Ltd. All rights reserved.

\section{Introduction}

Major depressive disorder (MDD) and generalized anxiety disorder (GAD) are highly prevalent and frequently comorbid diagnoses. A majority of individuals with MDD report a lifetime history of one or more anxiety disorders (Fava et al., 2000; Kaufman \& Charney, 2000; Kessler et al., 1996). GAD in particular is highly comorbid, with $80-90 \%$ of individuals meeting criteria for GAD having at least one other lifetime psychiatric disorder, and 60-70\% having a lifetime history of MDD (Carter, Wittchen, Pfister, \& Kessler, 2001; Kessler, DuPont, Berglund, \& Wittchen, 1999). MDD/GAD comorbidity occurs at least as frequently as MDD without GAD and much more frequently than GAD without MDD (Mineka, Watson, \& Clark, 1998). The fact that comorbidity between GAD and MDD is more the rule than the exception can be observed as early as adolescence (Van Lang, Ferdinand, Ormel, \& Verhulst, 2006).

MDD and GAD are accompanied by overlapping, perhaps indistinguishable, genetic liabilities (Hettema, Neale, Myers, Prescott, \& Kendler, 2006), and a number of shared symptoms such as fatigue, difficulty concentrating, sleep disturbance, and agitation (Zimmerman \& Chelminski, 2003). This poses a significant challenge for

\footnotetext{
Research described in this article was supported by NIH grants MH067447 and DA031579.

* Corresponding author at: Department of Psychology and Neuroscience, Duke University, Box 90086, 417 Chapel Drive, Durham, NC 27708, United States. Tel.: +1 9196605709.

E-mail address: tjstraum@duke.edu (T.J. Strauman).
}

developing reliable and valid diagnostic guidelines, for identifying common and unique etiological factors, and for translating research findings into effective treatments (Brown \& Barlow, 2009). It also highlights the need for theory-based hypotheses concerning shared and unique psychopathological mechanisms. Without such a theory-based approach, we run the risk of continuing to develop our understandings of each disorder primarily in isolation, rather than on building our understanding of disorders as they most commonly develop and occur, which is in the context of the other disorder. One possibility for an overarching theory linking mood and anxiety disorders is to apply principles of self-regulation to understanding anxious/depressive comorbidity.

\section{Regulatory focus theory}

Broadly speaking, self-regulation is a coordinated set of psychological processes guiding goal-directed behavior (Carver \& Scheier, 1990; Karoly, 1999). Self-regulation occurs both consciously and unconsciously, involving goals at varying levels of abstraction. Similarly, self-regulation has both reflexive/automatic and intentional/agentic components (Bandura, 2001). While theories of self-regulation acknowledge that human behavior reflects genomic, neural, and physiological influences, they also argue that a core aspect of human behavior is the effort to purposefully regulate behaviors, thoughts, and emotions to achieve desired goals, bring behavior in line with standards, control attention and thoughts, and manage affect (Posner \& Rothbart, 2000). These capabilities 
are thought to have evolved to deal with challenges that arise in our physical and social environments (Leary \& Buttermore, 2003). However, these same capabilities also can render us vulnerable to a range of emotional disorders (Karoly, 1999).

Although there are a number of well-validated models of selfregulation (e.g., Forgas, Baumeister, \& Tice, 2009), this article will examine the relevance of regulatory focus theory (RFT; Higgins, 1997) for understanding GAD and MDD/GAD comorbidity. RFT is a model of self-regulation that proposes two motivational systems, the promotion and prevention systems. Self-regulation with a promotion focus involves advancement and accomplishment. The promotion system is sensitive to the difference between the status quo or neutral state and a noticeable positive deviation from that state (the difference between " 0 " and " +1 "). Pursuing promotion goals means making good things happen and engenders an eager, positive-outcome-focused motivational state. From a signal detection theory standpoint, a promotion orientation involves focusing on maximizing "hits", regardless of the number of misses or errors (Higgins, 1998). As a result, the perception of progress toward or attainment of a promotion goal results in happiness and joy, whereas lack of progress results in sadness and disappointment.

In contrast, self-regulation with a prevention focus also occurs in the service of a desired end-state but involves concerns with security, protection, and responsibility. The prevention system is sensitive to the difference between the status quo or neutral state and a negative deviation from that state (the difference between "0" and "-1"). Pursuing prevention goals means keeping bad things from happening and engenders a vigilant, negative-outcome-focused motivational state. Again from a signal detection theory standpoint, a prevention orientation involves focusing on avoiding errors rather than maximizing "hits". Thus, stimuli indicating potential threats or dangers are the most salient, and perception of these possibilities and/or the failure to avoid the undesired outcome results in feelings of anxiety and dread. When an individual in a prevention state is successful in avoiding the undesired outcome, she or he typically experiences feelings of quiescence and calm or relief.

While both systems serve the purpose of pursuing positive endstates, each is associated with distinguishing motivational states, strategies for goal pursuit, and affective consequences of perceived success and failure. Support for the distinct nature of these systems can be found in recent studies indicating that promotion and prevention goals are associated with discriminable cortical activation patterns (Amodio, Shah, Sigelman, Brazy, \& Harmon-Jones, 2004; Eddington, Dolcos, Cabeza, Krishnan, \& Strauman, 2007). It is also important to note that while promotion/prevention systems share some similarities with constructs such as BAS/BIS, they are conceptually, functionally and neuro anatomically distinct (Eddington et al., 2007; Strauman \& Wilson, 2010). Among other differences, BIS and BAS do not incorporate higher-order cognitive aspects of human goal pursuit such as personal goal representations.

The engagement of the prevention and promotion systems tends to be self-sustaining when the activated system is being effective in achieving goals (Higgins, Roney, Crowe, \& Hymes, 1994). This occurs for several reasons. First, activation of either system increases the accessibility of system-relevant goals and constructs, which increases the likelihood that the individual will interpret social stimuli in ways that are consonant with that system. As a result, the individual becomes more likely to notice opportunities to pursue goals or feedback relevant to that system (and to construe complex or ambiguous situations in terms of the system currently active). Second, perceived effectiveness within either system creates positive affect, which serves to reinforce use of that system and the associated regulatory strategies.

With regard to what "success" per se means, it is worth noting that the two systems differ (Higgins, 1997). Within the promotion system, a stimulus indicating movement toward the desired goal (a gain of "+1") represents success feedback, while a stimulus indicating no movement toward the desired goal (a non-gain of remaining at " 0 ") represents failure feedback. Thus, within the promotion system, the more progress an individual makes in moving toward a promotion goal, the more motivated that individual becomes to continue goal pursuit. In contrast, the nature of the prevention system dictates that a stimulus indicating that a satisfactory state has been maintained (a non-loss of remaining at " 0 ") represents success feedback, while a stimulus indicating increased likelihood of not maintaining a satisfactory state (a loss from moving to " -1 ") represents failure feedback. Success in prevention goal pursuit (although not in promotion) is often experienced as an "all or nothing" enterprise; either one has avoided all potential dangers or threats or one has not. In both systems, perceived failure in goal pursuit results in negative affect which can serve the adaptive purpose of motivating the individual to continue goal pursuit efforts, alter strategies, or disengage from one goal and initiate pursuit of another.

RFT posits that the two modes of self-regulation (i.e., promotion and prevention) are mutually inhibitory, such that when one mode is blocked, interrupted, or unavailable (e.g., due to some dysfunction within that system), the other mode may come on-line as a compensatory mechanism (Higgins, 1998). Thus while an individual may have promotion and prevention goals related to the same topic or issue, only one system is actively engaged in pursuing a goal at a given moment. Since promotion and prevention systems operate in the service of goal pursuit, and goal availability and accessibility change continuously over time, under normal circumstances people will switch systems on a regular basis (Shah, Higgins, \& Friedman, 1998). This mutual inhibition, combined with an ability to disengage from specific goals when attainment is unlikely, creates both flexibility and efficiency in goal pursuit (Shah \& Higgins, 1987). Which system is engaged at any particular time is influenced by features of particular situations and by individual differences in chronic regulatory orientation (Higgins, 1997).

While healthy individuals are capable of both types of goal pursuit and switching between systems, the relative strength of orientation toward promotion vs. prevention is an individual difference that tends to be stable over time (Strauman, 1996). A primary determinant of this regulatory orientation is socialization (Higgins, 1989). In a prospective longitudinal study, Manian, Papadakis, Strauman, and Essex (2006) found that differences in maternal parenting behaviors at age 3 predicted the strength of promotion vs. prevention orientation when children were in first grade. Interestingly, Manian et al. observed that children's approach and avoidance temperaments did not predict individual differences in prevention and promotion orientation, suggesting that regulatory focus is not biologically based but rather represents a developmentally distinct, socially influenced mechanism for self-regulation of goal pursuit.

\section{Regulatory focus and psychopathology: depression vs. anxiety}

What is the role of these self-regulatory systems in vulnerability to types of psychopathology such as anxiety and mood disorders? To answer this question, it is crucial to distinguish between occasional and chronic self-regulatory failure because theories such as RFT postulate that the two scenarios would have very different consequences (e.g., Karoly, 1999; Strauman, McCrudden, \& Jones, 2010). Intermittent, routine failure in personal goal pursuit is presumed to be a ubiquitous experience, and the acute negative affective state that results is likely to serve the purpose of helping the individual adapt her/his goal pursuit in more effective ways. Chronic self-regulatory failure, on the other hand, increases vulnerability to pathogenic changes in the overall functioning of the two systems which, in turn, increases risk for 
psychopathology (Higgins, 1989; Papadakis, Prince, Jones, \& Strauman, 2006).

Chronic failure within the promotion system decreases strength of engagement in system-related goal pursuit because the reduction in eagerness from chronic failure is a non-fit for promotion (Higgins, 2006). This weakened engagement means that individuals are less likely to see promotion goals as potentially attainable (i.e., reduced optimism) and therefore less likely to pursue them (Miller \& Markman, 2007). As a result, they have fewer opportunities to experience the positive motivational and affective consequences associated with making progress toward a promotion goal, and are much more likely to experience the negative consequences of failing to make progress (Förster, Grant, Idson, \& Higgins, 2001). If this weakened engagement is not interrupted in some way, it can become a self-perpetuating cycle that ends in dysphoric affect, decreased incentive motivation, and negative self-evaluation - symptoms of depression indicative of a downregulated state caused by a chronic inability to "make good things happen" (Strauman, 1992). Weakened engagement in promotion goal pursuits would also generally reduce the attraction of positively valenced objects and activities related to promotion/gain concerns, so that the individual would feel less attracted to potential accomplishments and advancements. The positive value of such objects and activities would decrease even for goals unrelated to the specific failures that were experienced, contributing to the characteristic depressive symptom of "having no interest in doing things" (Higgins, 2006).

Consistent with this view, there is increasing evidence that depression both results from and maintains disruption of the psychological and biological mechanisms of incentive motivation (Dickson \& MacLeod, 2004; Sutton \& Davidson, 1997; Tomarken \& Keener, 1998; Watson, Wiese, Vaidya, \& Tellegen, 1999) and that dysfunction of self-regulation is a risk factor for depression (Karoly, 1999; Kasch, Rottenberg, Arnow, \& Gotlib, 2002; Lewinsohn, Allen, Seeley, \& Gotlib, 1999). Eddington et al. (2009) recently provided fMRI evidence that individuals with depression show reduced activation in an area of the left orbitofrontal cortex previously associated with priming of promotion goals (Eddington et al., 2007). These findings support the prediction that chronic failure to attain promotion goals can lead to a weakening of the promotion system, and that at least for a subset of individuals this weakened engagement in the promotion system is fundamental to the phenomenology of depression.

The mechanisms linking chronic failure in promotion goal pursuit to weakened engagement within the promotion system are not yet entirely clear. There are at least three possibilities and they are not mutually exclusive. The first, discussed above, is that the experience of repeated failures would produce a hypo-eagerness that is a non-fit with the promotion system. The non-fit leads to weakened engagement in goal pursuits, which in turn produces a generalized decrement in attraction toward promotion-related objects and activities. A closely related possibility is that the experience of repeated failure creates a cognitive barrier in that the individual believes that the probability of a positive outcome is either zero or so small as to be insignificant. As a result, it would become increasingly difficult to engage in promotion goal pursuit. This potential explanation closely resembles the theory of hopelessness depression (Abramson, Metalsky, \& Alloy, 1989). It is also possible that under conditions of chronic promotion failure, the level of positive feedback indicating promotion success (or at least progress) could drop below some critical minimum value needed to maintain the activity of the system. As a result, the system would simply fail to activate in response to most (or all) cues for goal pursuit. This perspective can be traced to the classic work by Akiskal and McKinney (1973) that described depression as a "reversible functional derangement of the mechanisms of reinforcement" (p. 22). Such a down-regulation process could be potentially adaptive in situations in which continued investments of energy are not likely to yield anything for the individual while at the same time depleting her/him of resources (Nesse \& Ellsworth, 2009).

It is worth noting that these possibilities are consistent with current approaches to depression treatment. For example, behavioral activation strategies (Jacobson, Martell, \& Dimidjian, 2001) involve getting people to become more active and eagerly engaged with the expectation that in order to feel better a person must do things. Although behavioral activation techniques were developed with a conceptual emphasis on the behavioral activation system rather than on cognitive-motivational processes, one could likewise interpret these strategies as an effort to "prime the pump" of the promotion system - that is, instigating eagerness and a focus on advancement. This strategy is consistent with RFT since increased eagerness in pursuing goals fits the promotion system, and this increase in regulatory fit would strengthen engagement in the goal pursuits. The strengthened engagement, in turn, would intensify attraction toward the objects and activities associated with goal pursuit, thereby counteracting the symptom of "having no interest in doing things" (Higgins, 2006). As another example, cognitive change strategies involve getting people to evaluate and test their beliefs about themselves and the world, including beliefs about the impossibility of success (e.g., Hollon, Thase, \& Markowitz, 2002). In the treatment for depression that originated from RFT, self-system therapy (SST; Strauman et al., 2006), both of these approaches are integrated; SST was found to be more efficacious than standard cognitive therapy for a subset of depressed individuals with a history of poor promotion system function (Strauman et al., 2006).

In contrast to chronic promotion system failure (which potentially results in a down-regulated, weakened engagement of the system), chronic prevention system failure leads to stronger engagement of the system along with a chronic hypervigilant state. Chronic prevention failure means that an individual perceives her or himself as continuously failing to "keep bad things from happening." Under such circumstances, the individual would be likely to experience feelings of being at risk or in danger, resulting in increased effort to be vigilant and avoid further harm (i.e., increased prevention focus). As a result, complex or ambiguous social stimuli would likely be interpreted as situations in which danger must be avoided rather than as opportunities for success. Such heightened accessibility of prevention goals would both maintain a vigilant emotional state and make it more difficult for the individual to use promotion-focused goal pursuit strategies where appropriate. In addition, vigilance is a fit for the prevention system that would strengthen engagement in safety-related and responsibility-related goal pursuits. Thus, the hypervigilance from chronic prevention failure, by strengthening engagement, would intensify reactions to potential threats and dangers, including threats and dangers beyond those related to the failures themselves, thereby yielding a generalized increment in anxiety - and potentially, generalized anxiety disorder (Higgins, 2006).

In addition to intensifying and generalizing reactions from stimuli related to prevention goals to more broad categories of threat, a mechanism consistent with cognitive models of hypervigilance (e.g., Leahy \& Holland, 2000), we also suspect that increased engagement of the prevention system may lead to a different kind of generalization in which discrete prevention goals become global and non-specific. In the face of heightened prevention focus, a specific (and adaptive) goal such as not being late to a job interview may generalize to not being late to anything - creating an everincreasing demand on the individual. These types of more global prevention goals are likely to be particularly problematic because under many circumstances, the only information that the individual has available regarding their progress in pursuit of a prevention 
goal is whether "bad things have been avoided" up to that point. Regardless of the desirability of the goal, guarantees of permanent future avoidance of negative consequences are difficult to obtain. For example, if one is pursuing the prevention goal of avoiding car accidents, the "success" of avoiding an accident only applies to the drive one has finished; accidents remain a potential danger for all future drives. In contrast, were this endeavor to be reframed as a generalized promotion goal (e.g., to arrive at all destinations in good shape), one would receive achievement related success feedback after making progress in each step of the journey. We hypothesize that globalized prevention goals contribute to a hyperactivated prevention state because they are difficult to attain (creating additional focus for vigilance while also providing increased opportunities for prevention failure).

Another consequence of strengthened engagement of the prevention system and resulting hypervigilance is that the individual is likely to pursue goals within a prevention framework regardless of whether that regulatory approach is most suitable. But is the type of goal pursuit, i.e., promotion vs. prevention, really so critical to an individual's experience of success or failure? A growing experimental literature in applied as well as basic research settings offers considerable evidence for the importance of the promotion/ prevention distinction in predicting success within a broad array of situations and events (e.g., Bryant \& Dunford, 2008; Kark \& Van Dijk, 2007; Sassenberg \& Woltin, 2008). Consider the following example. For many young people, gaining acceptance to college is a highly desirable positive end-state with substantial implications for self-worth. According to RFT, this end-state can be construed as a promotion goal (get accepted into college) or a prevention goal (don't get rejected from college). Note how the end-state itself is the same, but the strategies that one might use, and the motivational and emotional states that would accompany the receipt of feedback regarding progress, would vary greatly depending on which system was engaged. From a promotion focus standpoint, success in pursuit of this particular goal merely requires one desirable college to accept the individual; once that occurs, she or he indeed has "made something good happen". In contrast, within a prevention focus, every rejection letter is motivationally significant feedback indicating that "something bad is happening." As another example, looking out the windows of a country cottage can be an opportunity for either promotion or prevention. In a promotion state, the view out of any one window is sufficient to enjoy a beautiful glimpse of nature outside. But in a prevention state, every single window must be checked to ensure it is safely locked against potential intruders. So whereas RFT does not postulate that one type of regulatory focus is inherently more adaptive than the other, clearly some types of feedback or strategies may be more consistent with one system vs. the other.

While some of the mechanisms by which chronic failure leads to psychopathology have yet to be empirically tested, there is evidence for the overall association between regulatory failure and symptoms of psychological disorder. A series of studies have used the concept of self-discrepancies to study the impact of chronic promotion and prevention failure. According to self-discrepancy theory (SDT; Higgins, Bond, Klein, \& Strauman, 1986), people assess their progress toward important personal goals by comparing their actual self with two kinds of internalized standards or selfguides, the ideal self (who they wish and hope to be) and the ought self (who they think they should or ought to be). In the language of RFT, a discrepancy between actual and ideal selves (AI discrepancy) represents a non-achievement of a promotion goal (in this case, an ideal self-guide), whereas a discrepancy between actual and ought selves (AO discrepancy) represents a non-achievement of a prevention goal (in this case, an ought self-guide). Different studies used different instruments to quantify self-discrepancy, e.g., the Selves Questionnaire (SQ: Higgins, Klein, \& Strauman, 1985) or the Com- puterized Selves (CSQ; Shah \& Higgins, 2001). These studies have found positive correlations between the presence of depression symptoms and level of AI discrepancy (promotion failure) and between the presence of anxiety symptoms and level of AO discrepancy (prevention failure). Individuals with high levels of both $\mathrm{AI}$ and AO discrepancy report experiencing both depressive and anxious symptoms (e.g., Strauman, 1992). Of course, not all studies examining correlations between measures of self-discrepancy and measures of distress found discriminant associations between AI vs. AO discrepancy and depressive vs. anxious symptoms (Burch, Rivet, \& Laurenti, 2000; Tangney, Niedenthal, Covert, \& Barlow, 1999). Higgins (1999) noted that this variability is likely due to conceptual and methodological issues, including differences among studies in the assessment of actual-self attributes as well as personal goals, overlap between measures of the ought self and related constructs such as the undesired self or feared self, statistical power, the accessibility of individuals' ideal and ought selfguides, and perhaps most importantly, the comorbidity issues addressed below. Another important issue is the need to distinguish chronic failure from occasional failure and/or natural gaps between goals and achievement that occur as older goals are met or discarded and new ones are developed. Indeed, findings have become more consistent as measures are developed to be better able to distinguish between the two (Boldero, Moretti, Bell, \& Francis, 2005).

Although research exploring the implications of RFT for vulnerability to distress has primarily focused on the effects of chronic failure, it is worth noting that a traumatic failure is likely to have the same deleterious effects on the systems as does chronic failure. For instance, a violent attack on an individual represents a failure of an implicit but fundamental prevention goal related to keeping the self safe from harm (Brewin \& Vallance, 1997). Similarly, the sudden and unexpected loss of a job or spouse can result in perceived failures in fundamental promotion goals because of the roles that relationships and careers play in enabling people to make good things happen. Consistent with the literature on depression (e.g., Nesse \& Ellsworth, 2009), there are likely to be events which are relatively common causes of self-regulatory failure across individuals because some personal goals are widely shared within communities or cultures, often because they are goals tied to fundamental human needs and desires (Higgins, Strauman, \& Klein, 1986). Events that are less typical causes of self-regulatory failure probably depend for their effect on how they impact an individual's more idiosyncratic goals. Since both chronic and traumatic failure have the potential to dysregulate either (or both) systems, it is probably more accurate to refer to clinically important dysregulation of the promotion and prevention systems as resulting from "significant" failure experiences.

\section{Prevention system failure and vulnerability to generalized anxiety}

Although not a theory of psychopathology, RFT predicts that a hyperactive prevention system would be characterized by hypervigilance, a dominant negative outcome focus, and increased sensitivity to stopping a change from " 0 " to " -1 ", all in the effort to "keep bad things from happening". Unfortunately, this hyperactivity does not translate into increased effectiveness in reaching prevention goals, but actually hampers performance in the pursuit of prevention goals. This prediction draws on the classic curvilinear association between anxiety/arousal and task performance - the Yerkes-Dodson law (Yerkes \& Dodson, 1908). This well-established principle states that there is an optimal level of arousal for maximum performance (including performance of complex, multi-step tasks such as goal pursuit). At both extremes of low and high levels of arousal, performance is poor. The Yerkes-Dodson law has been validated in a variety of areas including trauma (McNally, 2003), 
job stress (Bhuian, Menguc, \& Borsboom, 2005), and academic stress (Bodas \& Ollendick, 2005; Keeley, Zayac, \& Correia, 2008; Sarid, Anson, Tyaari, \& Margalith, 2004) as well as the etiology of anxiety disorders (Shankman \& Klein, 2003).

In their prospective study of the development of individual differences in regulatory focus, Manian et al. (2006) observed the same curvilinear association between maternal parenting behaviors postulated to convey prevention-focused messages about the social world and individual differences in prevention focus among children three years later. This finding suggests that even on the level of teaching and modeling prevention, there may be degrees of emphasis by parents on "keeping bad things from happening" that are simply too intense and that have the paradoxical effect of reducing the child's ability to effectively pursue prevention goals. Thus, we postulate that there is an optimal range of activation for the prevention system, and that levels of activation exceeding the optimum values would be associated with less efficient selfregulation as well as hyperarousal (Higgins, 1989).

These observations provide a basis for linking prevention system dysfunction with anxiety symptoms and suggest a more specific vulnerability to generalized anxiety disorder. For example, a number of the features hypothesized to indicate a chronically hyperactive prevention system are consistent with GAD symptoms of worry, feeling keyed up, muscle tension, fatigue, and irritability. Also, as mentioned above, the hypervigilance from chronic prevention failure, by strengthening engagement, would intensify and broaden reactions to potential threats, which would produce a generalized increment in anxiety. Furthermore, it is plausible that the GAD symptom of having difficulty concentrating results from the challenge of pulling focus away from a scanning of the environment for prevention cues; i.e., constantly checking for potential threats. Similarly, the fatigue associated with GAD would be an expected secondary effect of the effort involved in being in a continuous heightened prevention state. Although the predictions of the RFT model regarding chronic failure and GAD are logically consistent and have some support from self-discrepancy research, there is not as much evidence available to support those predictions as is available regarding the link between promotion system hypoactivation and depression. As a result, additional work is needed to verify the predictions of the model. We will present some initial data below that suggest the value of additional research specifically focusing on the link between prevention system dysfunction and vulnerability to anxiety. We are not aware of other theories which predict how perceived failure could lead both to specific symptoms of anxiety and to a generalized anxious state resembling GAD.

\section{Regulatory focus and depressive/anxious comorbidity}

As described above, activation of the promotion vs. prevention system constitutes mutually exclusive ways of pursuing goals at any given point in time. Since significant failure within either system can lead to dysfunction of that system, and since the systems function in a reciprocally inhibiting manner, RFT has natural extensions to the question of comorbidity between anxiety (especially GAD) and depression.

For at least a subset of individuals, depression is associated with hypoactivation of the promotion system. When the promotion system is impaired in this way, prevention becomes the default option for goal pursuit. The less effective the promotion system and the longer its attenuated/ineffective state lasts, the more active the prevention system is likely to become. A recent neuroimaging study observed that depressed individuals showed an overall pattern of decreased promotion activation and increased prevention activation compared to controls (Eddington et al., 2009). We hypothesize that as the prevention system becomes more and more the individual's dominant mode of self-regulation due to weakening engagement within the promotion system, the individual becomes increasingly at risk for significant prevention failure through the mechanisms described previously. Thus, RFT suggests a self-regulatory "pathway" through which an underactive promotion system associated with depression can lead to a hyperactive prevention system and the associated psychopathology of GAD. This logic (a breakdown of reciprocal inhibition and normal effective function between approach-oriented and avoidance-oriented motivational systems) relates to the highly influential work of Mineka et al. (1998) on the behavioral activation and inhibition systems (BAS and BIS) in emotional disorders. However, as noted above, the promotion/prevention systems and BAS/BIS are distinct (Eddington et al., 2007; Strauman \& Wilson, 2010).

A model in which alterations in function in one system impact the other also may help to explain the vulnerability to depression among individuals with GAD. Chronic hyperactivity in the prevention system means that the individual will, on average, spend less time in a promotion-focused state and therefore be less likely to make progress toward important promotion goals - increasing the probability of significant promotion failure. The reduced eagerness from less promotion success and from negative feedback resulting from promotion failure could, in turn, further weaken engagement in the promotion system, which both increases the likelihood of depressive symptoms such as anhedonia, sadness, and loss of self-esteem (i.e., a generalized decrement in "making good things happen") while also paradoxically exaggerating the over-activation of the prevention system and maintaining the individual's GAD symptoms.

Both of these general cases illustrate that when one mode of goal pursuit becomes disproportionally active (prevention) or inactive (promotion), it not only necessarily impacts the degree of activation of the other system but also the typical adaptive "crosstuning" of the systems (Higgins et al., 1994). The adaptive switching of pursuit modes in response to an ever-changing and complex social environment is interrupted and results in heightened risk for the type of psychopathology associated with each of the two regulatory systems.

Of course, not everyone who is depressed is also anxious, and not everyone who is anxious becomes depressed. How does RFT understand these less common but still occurring "pure" cases? When an individual with an underdeveloped prevention system (most likely due to early socialization) experiences significant promotion goal pursuit failure, their promotion system would eventually show the attenuated activation characteristic of depression but their prevention system would be unable to compensate in the expected way. From an RFT perspective, such an individual would be vulnerable to depression but would be unlikely to experience generalized anxiety - an ironic consequence of exposure to parenting that did not sufficiently instantiate the capacity for prevention-focused self-regulation.

Another possibility is that an individual whose depression had resulted in the expected attenuation of the promotion system and compensatory hyperactivity of the prevention system might be fortunate enough to be successful in pursuing prevention goals, perhaps due to socialization that provided more adaptive shaping of prevention goals and strategies to be concrete, finite, and realistic. Success in prevention reduces vigilance, which would reduce the hyperactivation of the prevention system because reduced vigilance, being a non-fit for prevention, weakens engagement in the prevention system. Prevention success, then, would reduce the hyperactivity of the prevention system (Higgins, 2006). However, we would expect this person to be at heightened risk for the development of GAD should subsequent prevention failures shift their prevention system towards hyperactivity by increasing vigilance and therefore strengthening engagement in the prevention system. 
Yet another alternative consistent with RFT would be if someone who had been experiencing both depression and anxiety reached an "exhaustion" stage in which they no longer had the energy for goal pursuit. Gailliot, Schmeichel, and Baumeister (2006) reported that increased self-regulatory effort is required to control worry and anxious affect and this effort can be difficult for individuals to maintain, especially in the presence of depressive symptoms. In the absence of perceived effectiveness provided by progress in goal pursuit, such an individual might be unable to maintain activation in either system. This individual would no longer have the energy to be either eager or vigilant. At this point, the reciprocal coupling of the two systems could break down and we would expect the individual to be deeply depressed and likely be displaying some of the more vegetative symptoms of depression such as psychomotor retardation and excessive sleep. A final (and related) example would be of an individual whose experience of promotion failure was so catastrophic, and the resulting reduction in promotion system activation so profound, that the entire "self" (as an overarching cognitive/motivational structure) was overwhelmed and the individual ceased pursuing goals altogether. These last two types of cases would be discriminable by the fact that the former would have a history of vigilance and anxiety before the shift into a predominantly vegetative depressive state.

What about cases of generalized anxiety without depression? Such instances deriving from self-regulatory dysfunction would be expected among individuals whose hyperactive prevention system had resulted in an underactive promotion system but who had nevertheless been successful in meeting at least some promotion goals. A much less common instance of anxiety without depression would occur for individuals who had poorly developed promotion systems, such that they simply did not pursue promotion goals and therefore (ironically) did not experience promotion goal failure. Since these individuals would have been functioning in the social environment with just a single strategy for pursuing goals (prevention), we would expect this individual to have a history of generalized anxiety, as well as a history devoid of promotion-related successes and their accompanying feeling experiences (e.g., joy, enthusiasm, delight).

RFT suggests fewer routes to generalized anxiety without accompanying depression symptoms than to depression without accompanying generalized anxiety symptoms. This is perhaps not a coincidence given that, empirically, there are also fewer of these cases to explain. There is a natural asymmetry between the two systems that can be illustrated using a Bayesian analysis and the logic of inhibition. Depression involves very low activation of the promotion system, and generalized anxiety involves very high activation of the prevention system. Thus, given hyperactive prevention (generalized anxiety), hypoactive promotion (depression) is likely because a very strong prevention system will inhibit the promotion system and make it weaker. But given hypoactive promotion (depression), hyperactive prevention (generalized anxiety) need not occur because a weak promotion system could be associated with either a weak or a strong prevention system. Moreover, even if the prevention system is strong, it need not be at the hyperactive level that is associated with GAD. It could simply be at an effective level that occurs without generalized anxiety. This effective level of prevention would not - indeed, could not - be inhibited by a weak promotion system.

What about asymmetry of comorbidity from a self-regulatory perspective? Chronic prevention failure will produce both generalized anxiety and hypervigilance. This emphasis on strategic vigilance would necessarily decrease the likelihood of using eager strategies of goal pursuit. Reduced use of eager strategies is a non-fit for promotion and would weaken engagement in the promotion system; weakened engagement, in turn, would reduce attraction toward gains and advancements, producing the depres- sive symptom of "having no interest in doing things". Thus, chronic failure in prevention is likely to produce over time both generalized anxiety and depressive symptoms. Chronic promotion failure, on the other hand, will produce depression and hypo-eagerness; such reduced emphasis on strategic eagerness may or may not increase the likelihood of using vigilant strategies of goal pursuit. And even if reduced eagerness did increase vigilance to some extent, it need not produce hypervigilance. It could produce a level of vigilance that facilitates effective prevention and not GAD.

\section{Findings from exploratory analyses}

While the extension of RFT into the realm of comorbidity between depression and generalized anxiety is largely theoretical at this point, there is evidence available which supports some of the predictions outlined above. Below we will discuss the results of analyses conducted on two existing datasets. There are obvious limitations inherent in using previously gathered data to speak to issues unrelated to the original study design. We wish to make clear that we are not presenting this data as definitive proof of the theory or arguing that there is only one way to interpret it. However, we do believe that the fact that these results support the theory outlined above is significant, and suggests that the theory is worthy of further investigation.

In a recent pilot study, we assessed a total of ninety-three graduate/professional students. The sample was $80 \%$ female, with a mean age of 26.33 years $(S D=4.37$; range $=21-48$ years $)$ and predominately Caucasian (72\%). The participants completed the Computerized Selves Questionnaire (CSQ; Shah \& Higgins, 2001), the Beck Depression Inventory (BDI; Beck, Ward, Mendelson, Mock, \& Erbaugh, 1961), and the State scale of the State-Trait Anxiety Inventory (STAI; Spielberger, 1985).

We hypothesized that despite the generally modest levels of symptoms reported on average, these subjects would evidence the previously demonstrated relationship between AI discrepancy and depressive symptoms, and between AO discrepancy and anxious symptoms. They did so. In a hierarchical multiple regression analysis, perceived promotion failure predicted depressive symptoms after controlling for anxious symptoms and prevention failure, $R^{2}=.04, p<.05, \beta=.22$. Likewise, perceived prevention failure discriminantly predicted anxious symptoms after controlling for depressive symptoms and promotion failure, $R^{2}=.03$, $p<.05, \beta=.19$.

We then divided the subjects into four groups according to their current levels of perceived promotion or prevention failure, as determined by a composite measure of actual-self:self-guide distance and the perceived importance of the self-guides. Group 1 was selected to be above the median on both kinds of failure; Group 2 was above the median on promotion failure but not prevention failure; Group 3 was above the median on prevention failure but not promotion failure; and Group 4 was below the median on both kinds of failure. We then assessed whether there was a group by distress type interaction in terms of depressive vs. anxious symptoms.

In addition to the previously established associations between promotion failure and depression symptoms and between prevention failure and anxiety symptoms, we also expected that failure in one system would negatively impact the functioning of the other system. Specifically, we expected that individuals with promotion failure would not only report more depressive symptoms than the group with neither type of failure, but they also would report a level of anxiety symptoms that would be less than those individuals with substantial prevention failure but greater than those experiencing failure in neither system. Similarly, we expected that individuals with prevention failure would not only show elevated 
anxiety scores, but would also show a level of depressive symptoms that would be less than those individuals with substantial promotion failure but greater than those experiencing failure in neither system. We conducted a two-way analysis of variance and found the predicted associations between group status and type/level of distress (see Table 1 ). There was a significant main effect for group, $F(3,97)=6.42, p<.01$, as well as a significant group by symptom type interaction, $F(3,97)=2.55, p<.05$.

Within this study, individuals who experienced failure in one system not only showed elevations in symptom scores relevant to that system, but also showed elevations in symptom scores relevant to the other system, thus giving evidence that failure in one system negatively impacted the functioning of the other system. Of course, whereas the BDI and STAI scores showed the expected associations with promotion and prevention failure, respectively, the average scores in all groups remained relatively low. We would expect greater levels of distress in a sample drawn from a population that was more diverse than successful graduate students in a competitive academic environment.

We do not wish to make too much of these findings given the relatively small effect sizes and samples, but they do reflect the kind of asymmetry in comorbidity found in clinical populations. Consider Group 2 (promotion failure) and Group 3 (prevention failure) in comparison to Group 4 (controls). The promotion failure group was about $15 \%$ more anxious than the controls, which is in the predicted direction of depression producing anxiety but nonetheless is modest in size and certainly allows for depression from promotion failure to occur without anxiety. In contrast, the prevention failure group is about $70 \%$ more depressed than the controls, which is in the predicted comorbid direction and is a stronger effect. Apparently there is much less room for anxiety from prevention failure to occur without depression. Future research will need to confirm these intriguing asymmetrical effects.

In order to further examine the predictions of RFT as related to anxious/depressive comorbidity, we also conducted post hoc analyses using data from the Eddington et al. (2009) fMRI study of depression. Previous research has found that promotion and prevention goals can be activated via semantic priming and result in distinct patterns of cortical activation - with activity in the left orbital prefrontal cortex (OPFC) reflecting activation of the promotion system and activation in the right OPFC reflecting activation of the prevention system (Eddington et al., 2009). RFT predicts that depression is associated with hypoactive promotion systems and hyperactive prevention systems (compared to healthy individuals). We expected that there would be variation within the Eddington et al. (2009) depressed participants, such that individuals with higher levels of prevention failure would report more GAD symptoms and manifest greater right OPFC activation compared to both age-and-gender-matched controls and depressed participants with lower levels of prevention failure.

We examined data from 22 unmedicated adult patients meeting criteria MDD and 14 controls. Participants had been exposed to their promotion and prevention goal words embedded in a depth-of-processing task. Subjects were presented with 4 blocks of 16 words each. Unknown to the participants, within each block some words were the individual participant's promotion goals and

Table 1

Symptom scores by group.

\begin{tabular}{lllll}
\hline & Promotion & Prevention & BDI & STAI-S \\
\hline Group 1 & Failure & Failure & 5.89 & 41.95 \\
Group 2 & Failure & No failure & 5.74 & 38.95 \\
Group 3 & No failure & Failure & 4.31 & 40.15 \\
Group 4 & No failure & No failure & 2.54 & 33.42 \\
\hline
\end{tabular}

others were the participant's prevention goals (both identified from an interview approximately three weeks earlier). There were no differences between groups on neural activation associated with the task itself, indicating that any differences observed for incidental goal priming would not be accounted for by overall differences in task engagement or activity levels.

As previously reported for the promotion (vs. prevention) goal priming condition comparison, the control group showed significant activation in an area of the left OPFC, whereas the depressed patients showed significantly less activation in this region. Moreover, the depressed group showed significantly greater activation in an area of the right OPFC than the controls: $t(35)=3.47$, $p<.01$. Most importantly, when we examined activation in the right OPFC for depressed participants with vs. without GAD, the MDD/GAD participants manifested significantly greater activation at that locus, $t(20)=3.32, p<.05$. Thus, not only did this study observe neural correlates of compensatory prevention system activation among depressed individuals relative to controls, but it also found that individuals meeting diagnostic criteria for both MDD and GAD showed the specifically predicted pattern of neural activity. They manifested both attenuated left OPFC activation (a potential marker for a hypoactive promotion system) compared to controls and increased right OPFC activation (a potential marker for a hyperactive prevention system) compared to controls and depression-only participants.

\section{General summary and future directions}

RFT is applicable not only to depression and anxiety (specifically GAD) alone, but to the issue of comorbidity as well. With regard to co-morbidity, the theory predicts discriminant links between chronic prevention failure and GAD, while extensions of the theory predict pathways by which prevention failure can lead to promotion hypoactivity and related depression. Similarly, RFT can explain cases in which promotion failure-related depression leads to generalized anxiety, although it also accounts for cases in which it does not. The fact that RFT can accommodate both the rule and the exception reflects a potential strength of the theory; it draws on both universal human motivations and individual differences which affect them.

Especially intriguing is the RFT explanation for the well-known clinical asymmetry of GAD having a strong tendency to co-occur with depression rather than just occurring alone, compared to the weaker tendency of depression to co-occur with GAD rather than just occurring alone. RFT can account for this asymmetry by relating GAD to chronic prevention failure and hypervigilance, relating depression to chronic promotion failure and hypo-eagerness, and then working out the implications of these relations in terms of regulatory fit vs. non-fit and resulting strong vs. weak engagement. Specifically, we postulate that the chronic prevention failure associated with GAD produces hypervigilance that reduces strategic eagerness; reduced eagerness creates a non-fit with promotion that weakens engagement; and weakened engagement deintensifies (i.e., reduces) attraction toward gains and advancement - producing the major depressive symptom of "having no interest in doing things". This set of interrelations makes it likely that individuals suffering from GAD will eventually suffer from depression as well. In contrast, the chronic promotion failure associated with depression that reduces eagerness could create the hypervigilance associated with generalized anxiety, but it need not do so. It need not do so because despite the tendency for vigilance to increase in order to compensate for reduced eagerness, the increase could be to an effective level that yields prevention success rather than to a hypervigilant level that yields the prevention failure associated with GAD. 
RFT also can be studied on multiple levels of analysis. It has been successfully conceptualized and tested in terms of neural activation and as a psychological construct (Eddington et al., 2009). RFT is also a translational theory, yielding data relevant to treatment applications (Strauman et al., 2006). Also, the important components in terms of treatment applications (e.g., making good things happen vs. preventing bad things from happening; trying to strengthen engagement when depressed vs. trying to weaken engagement when anxious) are easily grasped and user-friendly for therapists and patients (Vieth et al., 2003). The concepts can be applied in both active treatments and within preventive interventions.

Another advantage is that the predictions of RFT share some conceptual similarities with existing theories of comorbidity, such as the tripartite and valence/arousal models (Shankman \& Klein, 2003). RFT links psychopathology with psychological processes that lead to well-being and offers specific predictions regarding how and for whom one disorder could lead to another.

Clearly, much of this work is conceptual and awaits empirical validation. For instance, additional evidence regarding the mutually inhibitory relationship between prevention and promotion would be useful. In terms of the proposed extension of RFT into comorbidity, important next steps for research include prospective longitudinal studies which follow individuals over time to see if dysfunction of each system affects the other as predicted and described above and whether exceptions to these relationships have the characteristics we have outlined. Similarly, examinations of the above hypothesized link between anxiety, over-activation of prevention system, and more generalized prevention goals would be useful. There are a number of other important questions that await exploration. For example, how do we distinguish between significant vs. adaptive failure and how might that vary across individuals? How do we measure regulatory orientation as well as experienced failure within each orientation? Although we await progress in answering these questions, current evidence suggests that RFT has great potential for helping understand, prevent, and treat GAD and depression and their comorbidity.

\section{References}

Abramson, L. Y., Metalsky, G. I., \& Alloy, L. B. (1989). Hopelessness depression: A theory-based subtype of depression. Psychological Review, 96, 358-372.

Akiskal, H. S. \& McKinney, W. T. (1973). Depressive disorders: Toward a unified hypothesis. Science, 182, 20-29.

Amodio, D. M., Shah, J. Y., Sigelman, J., Brazy, P. C., \& Harmon-Jones, E. (2004). Implicit regulatory focus associated with asymmetrical frontal cortical activity. Journal of Experimental Social Psychology, 40, 225-232.

Bandura, A. (2001). Social cognitive theory: An agentic perspective. Annual Review of Psychology, 52, 1-26.

Beck, A. T., Ward, C. H., Mendelson, M., Mock, J., \& Erbaugh, J. (1961). An inventory for measuring depression. Archives of General Psychiatry, 4, 53-63.

Bhuian, S. N. Menguc, B. \& Borsboom, R. (2005). Stressors and job outcomes in sales: A triphasic model versus a linear-quadratic-interactive model. Journal of Business Research, 58, 141-150.

Bodas, J., \& Ollendick, T. H. (2005). Test anxiety: A cross-cultural perspective. Clinica Child and Family Psychological Review, 8, 65-88.

Boldero, J. M., Moretti, M. M., Bell, R. C., \& Francis, J. J. (2005). Self-discrepancies and negative affect: A primer on when to look for specificity, and how to find it. Australian Journal of Psychology, 57, 139-147.

Brewin, C. R., \& Vallance, H. (1997). Self-discrepancies in young adults and childhood violence. Journal of Interpersonal Violence, 12, 600-606.

Brown, T. A., \& Barlow, D. H. (2009). A proposal for a dimensional classification system based on the shared features of the DSM-IV anxiety and mood disorders: Implications for assessment and treatment. Psychological Assessment, 21, 256-271

Bryant, P., \& Dunford, R. (2008). The influence of regulatory focus on risky decisionmaking. Applied Psychology: An International Review, 57, 335-359.

Burch, M. A., Rivet, K. M., \& Laurenti, J. K. (2000). Types of self-discrepancy and relationships to components of the tripartite model of emotional distress. Personality and Individual Differences, 29, 37-44.

Carter, R. M., Wittchen, H., Pfister, H., \& Kessler, R. C. (2001). One-year prevalence of subthreshold and threshold DSM-IV generalized anxiety disorder in a nationally representative sample. Depression and Anxiety, 13, 78-88.
Carver, C. S., \& Scheier, M. F. (1990). Origins and function of positive and negative affect: A control-process view. Psychological Review, 97, 19-35.

Dickson, J. M., \& MacLeod, A. K. (2004). Anxiety, depression, and approach and avoidance goals. Cognition and Emotion, 18, 423-430.

Eddington, K. M., Dolcos, F., Cabeza, R., Krishnan, K. R. R., \& Strauman, T. J. (2007) Neural correlates of promotion and prevention activation: An fMRI study using an idiographic approach. Journal of Cognitive Neuroscience, 19, 1-11.

Eddington, K. M., Dolcos, F., McLean, A. N., Cabeza, R., Krishnan, K. R. R., \& Strauman, T. J. (2009). Neural correlates of ideographic goal priming in depression: Goalspecific dysfunctions in the orbitofrontal cortex. Social Cognitive and Affective Neuroscience, 4, 238-246.

Fava, M., Rankin, M. A., Wright, E. C., Alpert, J. E., Nierenberg, A. A., Pava, J., et al. (2000). Anxiety disorders in major depression. Comprehensive Psychiatry, 41, 97-102.

Forgas, J. P., Baumeister, R. F., \& Tice, D. M. (Eds.). (2009). Psychology of selfregulation: Cognitive, affective, and motivational processes. New York, NY: Psychology Press.

Förster, J., Grant, H., Idson, L. C., \& Higgins, E. T. (2001). Success/failure feedback expectancies, and approach/avoidance motivation: How regulatory focus moderates classic relations. Journal of Experimental Social Psychology, 37, 253-260.

Gailliot, M. T., Schmeichel, B. J., \& Baumeister, R. F. (2006). Self-regulatory processes defend against the threat of death: Effects of self-control depletion and trait self-control on thoughts and fears of dying. Journal of Personality and Social Psychology, 91, 49-62.

Hettema, J. M., Neale, M. C., Myers, J. M., Prescott, C. A., \& Kendler, K. S. (2006). A population-based twin study of the relationship between neuroticism and internalizing disorders. American Journal of Psychiatry, 163, 857-864.

Higgins, E. T. (1989). Continuities and discontinuities in self-regulatory and selfevaluative processes: A developmental theory relating self and affect. Journal of Personality, 57, 407-444.

Higgins, E. T. (1997). Beyond pleasure and pain. American Psychologist, 52, $1280-1300$.

Higgins, E. T. (1998). Promotion and prevention: Regulatory focus as a motivational principle. Advances in Experimental Psychology, 46, 1-46.

Higgins, E. T. (1999). When do self-discrepancies have specific relations to emotions? The second-generation question of Tangney, Niedenthal, Covert and Barlow (1998). Journal of Personality and Social Psychology, 77, 1313-1317.

Higgins, E. T. (2006). Value from hedonic experience and engagement. Psychological Review, 113, 439-460.

Higgins, E. T., Bond, R. N., Klein, R., \& Strauman, T. J. (1986). Self-discrepancies and emotional vulnerability: How magnitude, accessibility, and type of discrepancy influence affect. Journal of Personality and Social Psychology, 31, 3-23.

Higgins, E. T., Klein, R., \& Strauman, T. J. (1985). Self-concept discrepancy theory: A psychological model for distinguishing among different aspects of depression and anxiety. Social Cognition, 3, 51-76.

Higgins, E. T., Roney, C. J., Crowe, E., \& Hymes, C. (1994). Ideal versus ought predilections for approach and avoidance: Distinct self-regulatory systems. Journal of Personality and Social Psychology, 66, 276-286.

Higgins, E. T., Strauman, T. J., \& Klein, R. (1986). Standards and the process of selfevaluation: Multiple affects from multiple stages. In R. Sorrentino \& E. T. Higgins (Eds.), Handbook of motivation and cognition. Foundations of socia behavior (Vol. 1, pp. 23-63). New York, NY: The Guilford Press.

Hollon, S. D., Thase, M. E. \& Markowitz, J. C. (2002). Treatment and prevention of depression. Psychological Science in the Public Interest, 3, 39-77.

Jacobson, N. S., Martell, C. R., \& Dimidjian, S. (2001). Behavioral activation treatment for depression: Returning to contextual roots. Clinical Psychology: Science and Practice, 8, 255-270.

Kark, R., \& Van Dijk, D. (2007). Motivation to lead, motivation to follow: The role of the self-regulatory focus in leadership processes. Academy of Management Review, 32, 500-528.

Karoly, P. (1999). A goal systems-self-regulatory perspective on personality, psychopathology, and change. Review of General Psychology, 3, 264-291.

Kasch, K. L., Rottenberg, J., Arnow, B. A., \& Gotlib, I. H. (2002). Behavioral activation and inhibition systems and the severity and course of depression. Journal of Abnormal Psychology, 111, 589-597.

Kaufman, J., \& Charney, D. (2000). Comorbidity of mood and anxiety disorders. Depression and Anxiety, 12, 69-76.

Keeley, J., Zayac, R., \& Correia, C. (2008). Curvilinear relationships between statistics anxiety and performance among undergraduate students: Evidence for optimal anxiety. Statistics Education Research Journal, 7, 4-15.

Kessler, R. C., DuPont, R., Berglund, R., \& Wittchen, H. (1999). Impairment in pure and comorbid generalized anxiety disorder and major depression at 12 months in two national surveys. American Journal of Psychiatry, 156, 1915-1923.

Kessler, R. C., Nelson, C. B., McGonagle, K. A., Liu, J., Swartz, M., \& Blazer, D. G. (1996). Comorbidity of DSM-III-R major depressive disorder in the general population: Results from the US National Comorbidity Survey. British Journal of Psychiatry, $57,17-30$.

Leahy, R., \& Holland, S. (2000). Treatment plans and interventions for depression and anxiety disorders. New York, NY: The Guilford Press.

Leary, M. R., \& Buttermore, N. R. (2003). The evolution of the human self: Tracing the natural history of self-awareness. Journal for the Theory of Social Behavior, 33, 365-404.

Lewinsohn, P. M., Allen, N. B., Seeley, J. R., \& Gotlib, I. H. (1999). First onset versus recurrence of depression: Differential processes of psychosocial risk. Journal of Abnormal Psychology, 108, 483-489. 
Manian, N., Papadakis, A., Strauman, T. J., \& Essex, M. (2006). Development of children's ideal and ought self-guides: The influence of parenting on individual differences in guide strength. Journal of Personality, 74, 1619-1645.

McNally, R. J. (2003). Psychological mechanisms in acute response to trauma. Biological Psychiatry, 53, 779-788.

Miller, A. K., \& Markman, K. D. (2007). Depression, regulatory focus, and motivation. Personality and Individual Differences, 43, 427-436.

Mineka, S., Watson, D., \& Clark, L. A. (1998). Comorbidity of anxiety and unipolar mood disorder. Annual Review of Psychology, 49, 337-412.

Nesse, R. M., \& Ellsworth, P. C. (2009). Evolution, emotions, and emotional disorders. American Psychologist, 64, 129-139.

Papadakis, A. A., Prince, R. P., Jones, N. P., \& Strauman, T. J. (2006). Self-regulation, rumination, and vulnerability to depression in adolescent girls. Development and Psychopathology, 18, 815-829.

Posner, M. I., \& Rothbart, M. K. (2000). Developing mechanisms of self-regulation. Development and Psychopathology, 12, 427-441.

Sarid, O., Anson, O., Tyaari, A., \& Margalith, M. (2004). Academic stress, immunological reaction, and academic performance among students of nursing and physiotherapy. Research in Nursing and Health, 102, 282287.

Sassenberg, K., \& Woltin, K. (2008). Group-based self-regulation: The effects of regulatory focus. European Journal of Social Psychology, 19, 126-164.

Shah, J. Y., \& Higgins, E. T. (1987). Expectancy X value effects: Regulatory focus as determinant of magnitude and direction. Journal of Personality and Social Psychology, 73, 447-458.

Shah, J. Y., \& Higgins, E. T. (2001). Regulatory concerns and appraisal efficiency: The general impact of promotion and prevention. Journal of Personality and Social Psychology, 80, 693-705.

Shah, J. Y., Higgins, E. T., \& Friedman, R. S. (1998). Performance incentives and means: How regulatory focus influences goal attainment. Journal of Personality and Social Psychology, 74, 285-293.

Shankman, S. A., \& Klein, D. N. (2003). The relation between depression and anxiety: An evaluation of the tripartite, approach-withdrawal and valence arousal models. Clinical Psychology Review, 23, 605-637.

Spielberger, C. D. (1985). Assessment of state and trait anxiety: Conceptual and methodological issues. Southern Psychologist, 2, 6-16.

Strauman, T. J. (1992). Self-guides, autobiographical memory, and anxiety and dysphoria: Toward a cognitive model of vulnerability to emotional distress. Journal of Abnormal Psychology, 101, 87-95.
Strauman, T. J. (1996). Stability within the self: A longitudinal study of the implications of self-discrepancy theory. Journal of Personality and Social Psychology, 71, 1142-1153.

Strauman, T. J., McCrudden, M. C., \& Jones, N. P. (2010). Self-regulation and psychopathology: Toward an integrative perspective. In J. Maddux \& J. P. Tangney (Eds.), Social psychological foundations of clinical psychology. New York, NY: Cambridge University Press.

Strauman, T. J., Vieth, A. Z., Merrill, K. A., Woods, T. E., Kolden, G. G., Woods, T. E., et al. (2006). Self-system therapy as an intervention for self-regulatory dysfunction in depression: A randomized comparison with cognitive therapy. Journal of Consulting and Clinical Psychology, 74, 367-376.

Strauman, T. J., \& Wilson, W. A. (2010). Individual differences in approach and avoidance. Behavioral activation/inhibition and regulatory focus as distinct levels of analysis. In R. H. Hoyle (Ed.), Handbook of personality and self-regulation (pp. 447-473). New York: Wiley-Blackwell.

Sutton, S. K., \& Davidson, R. J. (1997). Prefrontal brain asymmetry: A biological substrate of the behavioral approach and inhibition systems. Psychological Science, 8, 204-210.

Tangney, J. P., Niedenthal, P. M., Covert, M. V., \& Barlow, D. H. (1999). Are shame and guilt related to distinct self-discrepancies? A test of Higgins' (1987) hypotheses. Journal of Personality and Social Psychology, 77, 1313-1317.

Tomarken, A. J., \& Keener, A. D. (1998). Frontal brain asymmetry and depression: A self-regulatory perspective. Cognition and Emotion, 12, 387-420.

Van Lang, N., Ferdinand, R., Ormel, J., \& Verhulst, F. (2006). Latent class analysis of anxiety and depressive symptoms of the Youth Self-Report in a general population sample of young adolescents. Behaviour Research and Therapy, 44, 849-860.

Vieth, A. Z., Strauman, T. J., Kolden, G. G., Woods, T. E., Michels, J. L., \& Klein, M. H. (2003). Self-system therapy (SST): A theory-based psychotherapy for depression. Clinical Psychology: Science and Practice, 10, 245-268.

Watson, D., Wiese, D., Vaidya, J., \& Tellegen, A. (1999). The two general activation systems of affect: Structural findings, evolutionary considerations, and psychobiological evidence. Journal of Personality and Social Psychology, 76, $820-838$.

Yerkes, R., \& Dodson, J. (1908). The relation of strength of stimulus to rapidity of habit formation. Journal of Comparative Neurological Psychology, 18, 459-482.

Zimmerman, M., \& Chelminski, I. (2003). Generalized anxiety disorder in patients with major depression: Is DSM-IV's hierarchy correct? American Journal of Psychiatry, 160, 504-512. 